\title{
NoITE E DIA E ALGUNS MONOCROMOS PSÍQUICOS
}

\author{
Edson Luiz André de Sousa
}

Je me suis uni à la nuit

René Char

\section{Resumo}

$O$ artigo apresenta uma leitura do conto de Jack London "A sombra e o brilho" mostrando o funcionamento do princípio da mímesis no processo de identificação. Propõe-se a expressão monocromos psíquicos para esses espaços mentais de indiferenciação entre o eu e o Outro. Adota-se a tese de Caillois, que afirma que o eu é permeável ao espaço. Nessa perspectiva, o tema do duplo, amplamente desenvolvido por Freud, é fundamental. Partindo-se de notas sobre o trabalho do fotógrafo cego Bavcar, procura-se mostrar alguns traços da estrutura do olhar. $O$ artigo finaliza mostrando as conexões possíveis dessas reflexões para a prática psicanalítica.

Palavras-chave: Mímesis. Identificação. Monocromos Psíquicos. Jack London.

\section{NIGHT AND DAY - AND SOME PSYCHICAL MONOCHROMES}

\begin{abstract}
The paper presents a reading of Jack London's tale "The Shadow and the brightness", showing how the principle of mimesis works in the process of the identification. We propose to call psychical monochromes the spaces of mental indifference between the self and the other. We follow the thesis of Roger Caillois: "the self is permeable in the space". In this perspective, the subject of the double, developped by Freud is essential. We try to show the dialectic of the structure of the look based in some notes about the work of the blind photographer Bavcar. The article finish with showing the possibles connections of all these points with the clinical work.
\end{abstract}

Keywords: Mimesis. Identification. Psychical Monochromes. Jack London.

^ Professor do Departamento de Psicanálise e Psicopatologia e do PPG Psicologia Social do Instituto de Psicologia da UFRGS, e professor do PPG Artes Visuais do Instituto de Artes da UFRGS. Endereço: Rua Fernandes Vieira, 474/32, Porto Alegre - RS, CEP 90035-090.

E-mail: edsonlasousa@uol.com.br 


\section{Apontamentos noturnos Para UM dia longo}

Noite, dia, noite, dia, noite.... Interessa-nos a passagem. Hora que os anjos descem a terra para nos falar, desde que fiquemos em silêncio. Silêncio que precisamos em toda passagem. Do dia para a noite, da noite para o dia, da vida para a morte. Podemos evocar aqui John Cage e seu elogio ao silêncio: "Nenhum som teme o silêncio que o extingue. E nenhum silêncio existe que não esteja grávido de sons" (CAGE, 1985, p. 98).

Noite pulsão... Na noite os contornos se perdem. Por isso a obscuridade é uma das imagens do desamparo. Lugar do segredo. Segredo que se escreve. Recebi de um amigo uma caixa-poema de uma poetisa desconhecida, escondida talvez em alguma noite. ${ }^{1}$ Nina do Valle começa assim sua Doce Nave:

O tempo é o dia e a noite antes

e depois o dia

por que o olhar está olhando em linha reta

mas está vendo as curvas

o olhar diabólico vendo as diferenças entre

isso e aquilo, entre isso e o igual [...] (VALLE, 1985, p. 2).

$\mathrm{O}$ terror noturno de perder-se no espaço, no monocromo negro da noite e diluir-se em um mimetismo mágico. Possibilidade também do risco, de ser outro, de habitar outro tempo. Lugar do sonho. A noite diz do desejo, do sexual. Tempo rebelde a toda organização. Diluição. Noite. Desejo. Tocamos nesse ponto o sexual já que Lacan, no Seminário $O$ Desejo e sua interpretação, nos diz que "o desejo é uma realidade psicológica rebelde a toda organização" (LACAN, 2002, p. 20).

Dia fantasma. Um certo contorno um pouco mais definido, captura em um campo de reconhecimento. Dia que tenta elaborar a experiência da noite, em vão. O excesso de luz impede também de ver. Dia que faz o elogio do amor, este que pode ser revelado e que é alimentado por tudo que foi silenciado durante a noite.

Noite/dia, transposição de fantasmas, perigo. Roger Caillois inicia seu clássico "Mimetismo e a Psicastenia Legendária" com a lembrança: "Cuidado: de tanto brincar de fantasmas, nos tornamos um" (CAILLOIS, 1938, p. 86). Aponta, portanto, para o que faz diferença entre um e o outro, questão essencial em minha reflexão sobre monocromos, seja os de tinta e luz, seja o que estou nomeando como monocromos psíquicos. Diz Caillois: "De qualquer lado que se abordem as coisas, o problema último é afinal de contas este da distinção. Distinção do real e do imaginário, da vigília e do sono, da ignorância e do conhecimento" (CAILLOIS, 1938, p. 86).

\section{OS MONOCROMOS}

O ponto de partida é sempre o desassossego. Desassossego como uma espécie de desequilíbrio diante da simples visão do fio que temos que percorrer, fios que recortam o espaço e nos indicam que as superfícies são configurações do 
ideal. Não há como percorrer a vida como se fôssemos superfícies, nos lembra Schopenhauer (2001) no seu comovente A arte de ser feliz. ${ }^{2}$

O único percurso é como o da linha. Percursos por vezes cegos, no escuro, a sós. Há "só cegos" nesse espaço obscuro. A superfície rasgada testemunha a presença de um sujeito em deslocamento. De onde? Para onde? Questões cruciais que passamos na vida tentando responder. Então vejamos um pouco do desassossego de um grande poeta:

Cada qual tem o seu álcool. Tenho álcool bastante em existir. Bêbado de me sentir, vagueio e ando certo. Se são horas, recolho ao escritório como qualquer outro. Se não são horas, vou até o rio, como qualquer outro. Sou igual. E por traz de isso, céu meu, constelo-me às escondidas e tenho o meu infinito (PESSOA, 1999, p. 136 ).

Esse é um das centenas de fragmentos do "Livro do Desassossego" de Fernando Pessoa. Indica-nos o rumo de nossa reflexão: o tropeço que acerta o passo. Aliás, como Freud nos mostrou com todas as formações do inconsciente. Sem esse avesso da palavra, do gesto, do corpo, não teríamos como saber sobre o que efetivamente nos move. Este breve fragmento mostra de forma clara o princípio da busca da síntese com o outro, que podemos chamar de identificação e uma espécie de resto dessa operação, o que resiste a uma diluição completa (que só teremos na morte) e que conhecemos com o nome de sintoma (constelações escondidas que guardam os infinitos). Infinitos/enigmas, Infinitos/noites, Infinitos/ dias.

"Sou igual", princípio da mímesis, da busca do equilíbrio cinza que mistura todas as cores. Aqui neste ponto, impossível não evocar Roger Caillois novamente:

O desejo de assimilação ao espaço, de identificação à matéria aparece com frequência na literatura lírica: é o tema panteísta da fusão do indivíduo com o todo, tema onde precisamente a psicanálise vê a expressão de uma espécie de saudade (regret) da inconsciência pré-natal (CAILLOIS, 1938, p. 120).

"Sou igual", sem distinção de cores, apagando ilusoriamente essa linha do contorno entre um e outro, entre o eu e o espaço, princípio da mímesis. "O mundo tende em direção à uniformidade" (CAILLOIS, 1938, p. 118). Nesse ponto, Caillois busca apoio em Sigmund Freud e sobretudo em seu "Mais além do princípio do prazer". Freud, como sabemos, vai discorrer sobre a elasticidade da vida orgânica, e a pulsão de morte seria então essa força que tenta reequilibrar a perturbação que o estar vivo produz; "o fim em direção ao qual tende toda vida é a morte, pois o indivíduo, por razões internas, deseja o repouso, a igualização das tensões químicas, a insensibilidade, a inconsciência da morte". Freud é categórico: "a meta de toda vida é a morte" (FREUD, 1981, p. 2526).

"Sou igual" e "como qualquer outro" buscam essa imagem apaziguadora do eu que tenta cobrir-se com o manto produzido pelos espaços. "O Eu é permeá- 
vel ao espaço" (CAILLOIS, 1938, p. 112). Assim, os espaços escuros, com seus mantos negros, recobrem nossos corpos de medo e gozo. Os espaços escuros apagam provisoriamente os contornos do eu mostrando o quanto o mimetismo perfeito, a diluição completa no Outro (espécie de hemorragia narcísica) implicaria o que Caillois chama de despersonalização por assimilação ao espaço.

Depois do "Sou igual", um contraponto para nosso alívio, diz Pessoa: "e por trás disso". Alívio, há algo por trás, outra face, um sintoma que funciona como um osso na garganta da boca do espaço devorador. No entre-vírgulas, lemos "céu meu"; composição especular e sonora de um eu... eu...., céu meu, tema do duplo que funciona como um espelho em que buscamos um mínimo de foco. Vale ainda lembrar que temos um eu cujo acento o abre (éu) e um eu fechado (eu). Podemos também ler "seu meu", tema novamente do duplo e da fronteira inconstante entre o eu e o Outro. Os monocromos psíquicos buscam essa espécie de foco. As constelações escondidas que produzimos funcionam, portanto, como manchas que rasgam as superfícies uniformes. O monocromo obedece a uma espécie de tentação do princípio zero e que poderia figurar como uma operação matemática do tipo: 11 = zero, a diferença diluída, a operação finalizada, sem resto.

Podemos encontrar em um conto de Jack London (2002), "A sombra e o brilho", uma problematização desse estilo de operação matemática em que o zero seria uma espécie de invisibilidade. Esse pequeno conto surpreendente nos permitirá abrir espaços para as imagens dos monocromos que evoco neste artigo. London começa assim seu texto:

De um lado, havia Lloyd Inwood, alto, magro, bem apessoado, nervoso e moreno. De outro, Paul Tichlorne, alto, magro, bem apessoado, nervoso e louro. Um era a cópia do outro em tudo, exceto nas cores. Os olhos de Lloyd eram negros, os de Paul azuis. Quando o momento era de grande excitação, o sangue tornava as faces de Lloyd cor de azeitona, e as de Paul, cor de carmim. Mas tirando essa questão de coloração, eles eram parecidos como duas ervilhas (LONDON, 2002, p. 11).

Essas frases poderiam ser pensadas como duas pinturas monocromáticas, uma na busca do preto e outra na busca do branco. Lloyd Inwood como "O quadrado preto suprematista", pintura de Kazirmir Malevitch (1989), ${ }^{3}$ e Paul Tichlorne como "A composição suprematista branca", pintura também de Malevitch (1989). ${ }^{4}$ Visualmente o conto já nos mostra que a narrativa terá o ritmo do tic-tac, do zigzag, do Fort-Da. O desenho da frase evidencia um ritmo constante de rotação: de um lado, de outro... Toda a narrativa pulsará nesse tom, aliás, seguindo a estrutura clássica do conto, que é de contar sempre duas estórias. Há sempre uma mais visível e outra que corre no subterrâneo do texto, revelando um outro sentido. $\mathrm{O}$ prazer da leitura e a riqueza do conto estão nesse choque, na tensão entre as duas estórias que habitualmente surpreendem o leitor.

Então, é pelas cores que eles encontravam essa pequena diferença. O conto de London é quase pintura, uma palheta de tons, sombras, luzes, brilhos, reflexos. O que nos interessa aí é justamente esse trânsito de um para o outro, de Lloyd para 
Paul, do dia para a noite, do eu para o Outro. Trabalhamos aqui com o tema do duplo, clássico na história do pensamento e fundamental na história da psicanálise. A cor funciona no conto como dobradiça do texto. É ela que vai recortando as posições ora de um, ora de outro. Trata-se, portanto, de uma "cor ação". Batimentos que embalam a rivalidade feroz entre os dois personagens. Göethe (1993), em sua Doutrina das cores, já no prefácio enfatiza a relação entre cor e ação. "As cores são ações e paixões da luz. Neste sentido podemos esperar delas alguma indicação sobre a luz" (GÖETHE, 1993, p. 35). A narrativa de London vai intercalando os passos de Lloyd e de Paul e o leitor fica como que ofuscado nas passagens abruptas, violentas, surpreendentes entre um e outro. A passagem ofusca e nos informa sobre as posições de cada um. A dobradiça cumpre a função do terceiro, ponto de giro. No conto, é o narrador que se coloca nessa posição e é talvez a partir desse ponto que somos convidados a também ler o texto.

Mas essa amizade tão peculiar envolvia um trio, e o terceiro elemento era baixo, atarracado, gordo e preguiçoso - e, lamento dizer, esse terceiro era eu. Paul e Loyd pareciam ter nascido para ser rivais, e eu, para fazer as pazes entre eles. Crescemos juntos, os três, sendo que muitas vezes sobravam para mim os socos que eles desfechavam um contra o outro (LONDON, 2002, p. 12).

Socos como sobras, corpo-dobradiça que tenta aparar essa violência excessiva do encontro com o seu duplo. Se pensarmos nas duas pinturas de Malevitch que evoquei como metáforas que interpelam a luz e a escuridão, veremos que trata-se aí de experiências-limite. Göethe qualifica esses estados como "extremos".

A retina, segundo o efeito sobre ela exercido pela luz ou escuridão, se encontra em dois estados inteiramente opostos. Quando mantemos os olhos abertos num quarto totalmente escuro, sentimos uma certa ausência [...]. Ao voltarmos os olhos para uma superfície intensamente iluminada, eles se ofuscam [...]. Dessa maneira, cada um desses estados extremos ocupa toda a retina e, nessa medida, percebemos um só de cada vez (GÖETHE, 1993, p. 52).

Nessa passagem de um a outro delineamos a idéia da permeabilidade de cada corpo. Como sabemos, a permeabilidade da noite/obscura não é a mesma que a do dia/luz. Caillois insiste na permeabilidade ao escuro, espaços, portanto, que funcionam como mata-borrões e perfuram o contorno da pele deixando verter o escuro de dentro para o escuro de fora. ${ }^{5}$ Território precioso dos fantasmas e que muitos conhecem quando precisam acender a luz para distrair os pensamentos noturnos.

Lloyd e Paul sempre disputando. Certa vez, jogaram-se em um açude para ver quem tinha o maior fôlego. Não fosse nosso amigo narrador da história jogarse desesperado no açude e arrancá-los do fundo teriam morrido. 
Encontrei-os no fundo, agarrados com toda a força às raízes, as cabeças muito próximas, os olhos arregalados, cada um olhando fixamente para o outro. Estavam sofrendo horrivelmente, contorcendo-se de um lado para o outro na agonia da sufocação voluntária - porque nenhum dos dois daria o braço a torcer admitindo ter perdido (LONDON, 2002, p. 14).

Rivalidade feroz em tudo. Cada um busca superar o outro a todo custo. Assim se acompanham de muito perto, pois cada um funciona como a borda do outro. Estão lado a lado diante do pódium que só reserva lugar para um deles no topo. Pódium - figura emblemática de nossos tempos velozes em que o que importa não é chegar, mas sim chegar antes que o outro. Vale a lembrança de um surpreendente trabalho de Arthur Bispo do Rosário que vi na exposição "Ordenação e Vertigem." 6 Trata-se de três pequenos cubinhos em madeira numerados: 1, 2, 3. Estão colocados no formato de um pequeno pódium. Em cada cubo uma sílaba escrita: Pó - Di - Um. Assim, Bispo desmonta a palavra deixando verter uma interrogação que se fez para mim imagem: Pode um? Pergunta sobre o poder que abriu uma cicatriz no emblema que tanto nos fascina. ${ }^{7}$

Ambos vão estudar química. Lloyd começa a se interessar por uma reflexão sobre a cor. Parte da idéia de que cor é sensação e conclui, portanto, que "todos os objetos são negros no escuro, e no escuro é impossível enxergá-los. Se nenhuma luz incidir sobre eles, nenhuma luz será irradiada de volta em direção ao olho, e assim não teremos qualquer evidência visual de que eles existem" (LONDON, 2002, p. 19). Assim começa suas experiências de produzir o preto absoluto. Por outro lado, Paul também busca a invisibilidade, mas por outro caminho. Vai estudar a polarização da luz, a difração e a interferência. Tenta buscar a transparência absoluta. Busca soluções que modificam a estrutura molecular das matérias. A transparência possibilita que todas as luzes atravessem e então se torna invisível ao olho. Ambos vão obtendo sucesso em suas pesquisas. O narrador da história conta surpreso o susto que teve quando colocou o dedo na tinta preta que Lloyd preparara e viu seu dedo subitamente desaparecer. Paul também conseguiu um surpreendente resultado. Injetou o reagente que pesquisara em seu cão e nosso amigo narrador surpreendeu-se ao tropeçar no animal. Só pôde vê-lo quando Paul amarrou um lenço no pescoço do seu cão. Via então um lenço andando sozinho no espaço. (LONDON, 2002, p. 35).

Assim, Lloyd e Paul iam aprimorando cada vez mais seus experimentos. Um detalhe importante e revelador do impasse da invisibilidade surgiu nos experimentos de Paul. Seu cão invisível teve o crânio esmagado por uma forte pancada. Perdeu a vida e a invisibilidade. O curioso, contudo, foi a rapidez com que seu corpo se decompusera. Podemos aqui pensar a invisibilidade como uma espécie de apagamento do Outro e, portanto, a diluição completa do organismo no espaço, a mímesis perfeita, ou seja, não deixa de ser uma das figuras possíveis da morte. Diz Paul: 
Os reagentes que injetei em seu corpo eram inofensivos. Mas eram poderosos. Por isso, parece que, ao ocorrer a morte, eles provocam uma desintegração praticamente instantânea. Incrível! Realmente incrível! Bem, o que se tem a fazer é não morrer. os reagentes não fazem mal, desde que o organismo continue vivo. Simples portanto, basta não morrer. A morte vem atrapalhar nossos experimentos (LONDON, 2002, p. 35).

O que ainda não falei para vocês é que na busca da invisibilidade, nessa impregnação monocromática que ambos buscavam havia um detalhe que resistia e que funciona como o pequeno resto que denuncia a presença do sujeito. Lloyd não conseguira evitar uma pequena sombra que por vezes aparecia conforme o ângulo de incidência de luz e Paul também não evitara um pequeno brilho furtacor que por vezes também aparecia. Sombra e brilho: as imperfeições que nos preservam.

Como o leitor pode imaginar e como não poderia deixar de ser Lloyd e Paul se encontram na última cena do conto. Em uma quadra de tênis travam uma briga de morte. A invisibilidade que conseguiram os protege de mais uma interferência do amigo. Ele nada pode fazer a não ser aguardar o silêncio depois da batalha mortal.

Os segredos de suas maravilhosas descobertas morreram junto com Paul e Lloyd, tendo ambos os laboratórios sido destruídos pelos parentes enlutados. Quanto a mim, devo dizer que já não me interesso por pesquisas químicas e que a ciência é um assunto proibido em minha casa. Voltei a me dedicar às rosas. E dou-me satisfeito com as cores da natureza (LONDON, 2002, p. 47).

Os encontros com nossos duplos são os mais surpreendentes. Vivemos na pressão do princípio de que o semelhante produz o semelhante, esta fascinação em relação a sua própria imagem, narcisismo que nos lança em encontros inusitados e assustadores.

Um desses encontros que pude testemunhar aconteceu junto com meu amigo Evgen Bavcar. Grande escritor da luz, fotógrafo esloveno, cego desde a idade de 12 anos. Sua obra luminosa nos interpela sobre a condição de visibilidade. Ele é categórico ao afirmar que não podemos conceber uma arqueologia da luz sem considerar a escuridão, e sem elucidar o fato de que a imagem não é apenas alguma coisa da ordem do visual, mas pressupõe, igualmente, a imagem de obscuridade e das trevas.

Bavcar vai buscar no quadrado negro de Malevitch um estado primeiro da imagem, como uma borracha que precisa abrir espaços na folha repleta de traços. Ele insiste que o "quadrado negro" de Malevitch traz a esperança de um olhar para além do banal em que tudo se nivela. Diz ele: 
É preciso ir agora para trás do quadrado negro, concebendo as trevas não somente como superfície, mas, sobretudo como um volume, como um espaço existencial em que podem ainda aparecer algumas estrelas redentoras brilhando por sobre o novo (BAVCAR, 2001, p. 7).

$\mathrm{O}$ encontro do duplo aconteceu em uma manhã cinzenta e fria de uma segunda-feira em minha cidade natal, Pelotas. Saímos, com a filmadora na mão, para uma pequena caminhada nos arredores do hotel onde estávamos e Bavcar ia registrando suas últimas imagens de Pelotas, pois voltaríamos a Porto Alegre no início da tarde. Surpreendente a habilidade com que manejava a filmadora buscando ângulos impensados por nossa cegueira de videntes. Percebo uma certa inquietação dele no momento em que escuta um carroça que vem em nossa direção. Comenta sua fascinação por cavalos. Pude ver depois em alguns filmes sobre ele a destreza com que cavalga e o carinho com que trata os cavalos. Pediu-me para acompanhá-lo até a carroça. Um senhor "baixo, atarracado e gordo" como nosso narrador no conto do London e muito humilde recolhia restos de comida dos restaurantes para sua criação de porcos. Seu aspecto um pouco rude, com gestos bruscos e voz alta, contrastava com a suavidade da voz de Evgen, que queria saber mais sobre o cavalo. Ali o brilho dos olhos azuis de Bavcar encontrou a alegria e o orgulho desse desconhecido e seu cavalo. Conversaram durante longos minutos sobre raças de cavalos. No momento da despedida: a pergunta essencial que dá o tom à cena que vai acontecer. Sem esta pergunta a cena não teria adquirido sua magia, sua surpresa, seu desenlace impressionante. Bavcar pergunta como se chama o cavalo? A resposta é surpreendente: "Quero-ver"... Bavcar surpreso se aproxima do cavalo e o abraça dizendo: "Sou eu!" Encontra de forma inusitada seu duplo, seu nome trotando esquecido em uma rua sombria de uma cidade no sul do Brasil. Pede-me para tirar uma fotografia, que aliás saiu fora de foco e que talvez até por isso tenha sido publicada na abertura do seu belíssimo livro Memórias do Brasil. ${ }^{8}$

Então: quero ver... o que é possível ver? O que vemos? O que nos olha? ${ }^{9}$ Os monocromos psíquicos funcionam como manchas que tentam encobrir um pouco os buracos que o sexual produz. Sintomas costurando a borda de nosso radical desamparo diante do desejo do Outro. Monocromos que obedecem à cadência da repetição e que inscrevem em nosso corpo uma espécie de cegueira.

\section{Notas}

${ }^{1}$ Agradeço a Evandro Salles o precioso presente.

${ }^{2}$ Ver de SHOPENHAUER, Arthur. A arte de ser feliz. São Paulo: Martins Fontes, 2001.

${ }^{3}$ Esta pintura encontra-se na Tretiakov Gallery, em Moscou. (79,4 X 79,4 cm). Ver catálogo Kazimir Malevitch, Amsterdam, Stedelijk Museum, 5/3/1989 - 29/5/1989.

${ }^{4}$ Pintura no acervo do Museu de Arte Moderna de Nova York (79,4 X 79,4 cm). Catálogo Kazimir Malevitch, op. cit.

${ }^{5}$ Ver a belíssima passagem de José Saramago, em Todos os nomes, São Paulo, Companhia das Letras, 1997, p. 177 "Homem, não tenhas medo, a escuridão em que estás metido aqui não é maior do que a que existe dentro do teu corpo, são duas escuridões separadas 
por uma pele, aposto que nunca tinhas pensado nisto, transportas todo o tempo de um lado para outro uma escuridão, e isso não te assusta, há bocado pouco faltou para que te pusesses aos gritos só porque imaginaste uns perigos, só porque te lembraste do pesadelo de quando eras pequeno, meu caro, tens de aprender a viver com a escuridão de fora como aprendeste a viver com a escuridão de dentro [...]"

${ }^{6}$ Exposição no Centro Cultural Banco do Brasil em São Paulo. Ordenação e Vertigem, agosto a outubro 2003. Curadoria Jane de Almeida e Jorge Anthonio e Silva.

${ }^{7}$ Podemos ainda ler “pó de um”, entonação que abre uma rima com a morte.

${ }^{8}$ Referência ao livro Memória do Brasil, organizado por Elida Tessler e João Bandeira, São Paulo, Editora Cosac \& Naify, 2003. Transcrevo aqui um fragmento da descrição de Evgen Bavcar da cena que referi no texto. "Em realidade, meu primeiro encontro com as ruas de Pelotas estava carregado de significações misteriosas. Penso seguidamente naquele cocheiro que trabalhava na coleta de lixo da cidade. Tendo sentido e ouvido o cavalo, eu quis me aproximar. Pedi gentilmente a seu dono se podia tirar uma foto do animal. Não se tratava, claro, de uma foto artística, mas a de uma identidade simples. Ele concedeume o favor, ordenando ao cavalo que não se mexesse. Aliás, o nome do cavalo era revelador para o meu desejo fotográfico “Quero-ver”! Esse encontro inesperado entre dois cúmplices fez rir muito meus acompanhantes, sobretudo Edson, que nos revelou o segredo do nome do cavalo. Imediatamente pensei numa célebre novela de Anton Tchekhov, Angústia. $\mathrm{O}$ escritor nos descreve a jornada de um cocheiro que tenta em vão contar a seus clientes apressados a morte de sua esposa. Como ninguém quer escutá-lo, ele acaba por contar sua história ao cavalo. Quanto a mim, infelizmente, não tenho às vezes sequer um cavalo ao alcance da mão. Que sorte, enfim, aquele dia em Pelotas em que tantos cúmplices me cercavam, Benjamin, Edson, o cocheiro, e também Quero-Ver! Nesses raros momentos, sinto a vida quase como uma dádiva. Se um dia voltar a Pelotas, farei o possível para reencontrar Quero-ver e fazer dele uma fotografia em cores. Talvez nesse dia ele também se sentirá mais livre, pois pedirei a seu dono um pequeno favor. Estou convencido de que concordará em retirar-lhe as viseiras por um instante."

${ }^{9}$ Ver neste ponto o livro de Georges Didi-Huberman "O que vemos, o que nos olha", São Paulo, Editora 34, 1998.

\section{REFERÊNCIAS}

BAVCAR, E. Memória do Brasil. In: TESSLER, E.; BANDEIRA, J. (Org.). São Paulo: Cosac \& Naif, 2003.

- O ponto zero da fotografia: catálogo da exposição na Galeria Sotero Cosme. Porto Alegre: Casa de Cultura Mário Quintana, 2001.

CAGE, J. De segunda a um ano: novas conferências e escritos de John Cage. Tradução de Rogério Duprat. São Paulo: Hucitec, 1985.

CAILLOIS, R. Le mythe et l'homme. Paris: Gallimard, 1938.

DIDI-HUBERMAN, G. O que vemos, o que nos olha. São Paulo: Editora 34, 1998. 
FREUD, S. Mais além do princípio do prazer. In: . Obras psicológicas completas. Madrid: Biblioteca Nueva, 1981.

GÖETHE, J. W. Doutrina das cores. Apresentação e tradução de Marco Giannotti. São Paulo: Nova Alexandria, 1993.

LACAN, J. O desejo e sua interpretação: Seminário 1958-1959. Porto Alegre: Associação Psicanalítica de Porto Alegre, 2002. p. 20. Publicação não comercial; para circulação interna da Associação Psicanalítica de Porto Alegre.

LONDON, J. A sombra e o brilho. In: COLETÂNEA O Outro: três contos de sombra. Rio de Janeiro: Dantes, 2002.

MALEVITCH, K. O quadrado preto suprematista. 1989. 1 original de arte (pintura). Encontra-se na Tretiakov Gallery em Moscou. (79,4 X 79,4 cm). Ver catálogo Kazimir Malevitch, Amsterdam, Stedelijk Museum, 5/3/1989-29/5/1989. . A composição suprematista branca. 1989. 1 original de arte. Pintura no acervo do Museu de Arte Moderna de Nova York (79,4 X 79,4 cm). Catálogo Kazimir Malevitch.

PESSOA, F. Livro do desassossego. São Paulo: Companhia das Letras, 1999.

SHOPENHAUER, A. A arte de ser feliz. São Paulo: Martins Fontes, 2001.

VALLE, N. Doce nave. Ilustrado por Evandro Salles. Brasília, DF: Barbárie, 1985.

SARAMAGO, J. Todos os nomes. São Paulo: Companhia das Letras, 1997. p. 177.

Recebido em: junho/2005

Aceito em: março/2005 